\title{
Gestational and Early-Life Renovation Associated With Asthma and Allergies Among Pre-School Children in Chongqing: A Cross-Sectional Study
}

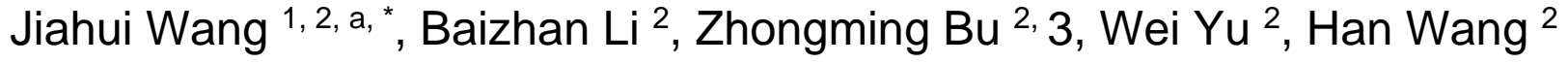 \\ ${ }^{1}$ Institute of Unban Construction, Hangzhou Polytechnic, Hangzhou, China \\ ${ }^{2}$ Key Laboratory of Three Gorges Reservoir Region's Eco-Environment, Ministry of Education, \\ Chongqing University, Chongqing, China
}

${ }^{3}$ Mechnical and Automotive Engineering, Zhejiang University of Science and Technology, Hangzhou, China

a jiahuiwang0921@163.com Keywords: housing environments; children's asthma and allergies; new furniture and new
decoration.

\begin{abstract}
The prevalence of asthma and allergies among children has increased in the last decades. Obviously genetic predisposition is the main factor, and also lifestyle factors, dietary habits and indoor environments are related to their high prevalence in many studies. A cross-sectional questionnaire study on home characteristics in 5,299 1-8 years old children was carried out in Chongqing to study the associations between decorated housing environments and children's asthma and allergies. The prevalence of doctor-diagnosed asthma was $10.0 \%$ for boys and $6.6 \%$ for girls. Multivariate logistic regressions were applied controlling for confounding factors. Having had new furniture and new decoration installed during one year before pregnancy had significant associations with children's asthma and allergies compared to other periods. Home new furniture one year before pregnancy was positively associated with wheezing ever [aOR $(95 \% \mathrm{CI}): 1.39(1.14,1.71)]$ and rhinitis ever [aOR $(95 \% \mathrm{CI}): 1.30(1.04,1.62)]$. Having had new decoration during pregnancy was also related to eczema ever and eczema in the past year. Stratifying for gender, there was a significant difference in the impacts of new furniture and new decoration on asthma and allergies between girls and boys, and girls had more health problems than boys. Opening windows of children's room more frequently could effectively reduce the prevalence of asthma and allergic symptoms.
\end{abstract}

\section{Introduction}

The indoor air quality has a direct impact on our health as most people around world spend up to $90 \%$ of their daily time indoor, e.g. at home, work or school. However, indoor environment is contaminated due to enormous use of building materials and furniture which are frequently introduced in remodeled and decorated houses under worldwide industrialization and urbanization [1]. According to their man-made fabrication process, volatile organic compounds (VOCs) and carbonyls have performed as a typical kind of indoor airborne chemical pollutants. They can easily release from these materials chronically and exist in indoor environment as a potential threat to human health $[2,3]$.

Exposure to these hazardous air pollutants (HAPs) may have potential adverse health effects to human body health. Some research [4] found that formaldehyde and VOCs are the most serious pollutants of indoor air, and they mainly effect irritation of the eye and throat. Decoration pollution can cause allergies and Sick Building Syndrome (SBS) [5], and when the concentration of indoor air reaches a certain high level, its risk to asthma will show up [6]. It had also been indicated that there were correlations between repeated exposure to formaldehyde and allergic asthma. Considering children's sensitivity to environmental pollutants due to their higher breathing rate to body size and continuing growth [7], some studies suggested that domestic exposure to formaldehyde could increase the risk of childhood asthma. Moreover, numerous studies reported that VOC was related to 
respiratory, allergic or immune effects [8]. Exposure to VOCs may result to asthma and asthmatic symptoms such as nocturnal breathlessness, increased bronchial responsiveness, and decreased lung function $[9,10]$. Some experiments concluded that the association between children's asthma prevalence and VOCs was statistically significant [11].

Most published studies on asthma and allergies among focused on indoor environments indicated building materials and decoration activities were found to have obvious relations to rhinitis, eczema and other allergic symptoms. Nevertheless, there are few published studies on children's asthma and allergies in relation to redecorated indoor environment. Relative research in Southwestern China is rather limited. The main aim of the present study is to estimate the prevalence of asthma and allergies among pre-school children in Chongqing, and its associations with redecorated housing environments.

\section{Materials and Methods}

\subsection{Study Design and Participants}

The subjects and questionnaire data were from the $\mathrm{CCHH}$ project, which has been introduced previously in detail [12]. In Chongqing, the questionnaire was distributed to parents of 7117 children (aged 1-8 years old) in 54 randomly selected kindergartens, located in 3 main urban districts of Chongqing. The questionnaire asked about basic family demographic information, diseases or symptoms in children and family members, building characteristics, current home environmental exposures and lifestyle habits based on the ISAAC study [13] and the DBH study [1]. Completed questionnaires were collected by teachers one week later. The ethical committee for the School of Public Health, Fudan University in Shanghai approved the procedure. All participants gave informed consent. More information about the Chongqing $\mathrm{CCHH}$ study has been detailed in previous publications [14, 15].

\subsection{Housing Renovation and Health Data}

Questions regarding the renovation information included (1) New furniture before pregnancy: "Had any new furniture been placed in your house during the last year before pregnancy?" (2) New furniture during pregnancy: "Had any new furniture been placed in your house during pregnancy?" (3) New furniture after giving birth: "Had any new furniture been placed in your house during the first year after giving birth?" (4) Renovation before pregnancy: "Had your house been renovated during the last year before pregnancy?" (5) Renovation during pregnancy: "Had your house been renovated during pregnancy?" (6) Renovation after giving birth: "Had your house been renovated during the first year after giving birth?" Each question about new furniture has three options, "yes, and a lot", "yes, a little"and"no". Questions about renovation has two options, "yes" and "no".

The target variables were prevalence of wheeze ever, rhinitis ever, eczema ever and related symptoms in the past year. Doctor-diagnosed asthma (D-asthma) and rhinitis (D-rhinitis) were also required. Indoor exposure was assessed based on questionnaire information focusing on home new furniture and new interior decoration or renovation, one year before pregnancy, during pregnancy, between $0-1$ years old, and after 1 year old. For new furniture there are 3 options to choose: (1) Large quantity; (2) Little; (3) No. And for new decoration or renovation there are also 3 options to choose: (1) Yes; (2) No; (3) Do not know. Large quantity and little were classified as buy new furniture, yes as had new decoration and do not know as missing at time of analysis. The frequency of opening windows of child's room was also considered. A opening window score was constructed from the 4 questions: (1) Frequency of opening the window of child's room in Spring; (2) Frequency of opening the window of child's room in Summer; (3) Frequency of opening the window of child's room in Fall; (4) Frequency of opening the window of child's room in Winter. Each "frequently" or "sometimes" responses was coded as " 0 ", "never" was coded as " 1 ". The total score was obtained by adding the 4 score for each subject. The OW-score (Continuous OW-score, range from 0-4) was then classified in two categories: open window frequently (score 0 and 1) and open window not frequently (score 2 , 3and 4). 


\subsection{Statistical Analysis}

All data analysis was performed using Statistical Package for Social Science (SPSS 18.0). Initially, pearson's chi-squared test was used to obtain the associations between redecorated housing environment and different building characteristics. Then using the same test to compare the prevalence of asthma and allergies for different related factors, and the associations between redecorated housing environments and children's asthma and allergies.

Next using multivariate logistic regression with adjustment for gender, age, house site, living near a main road or highway, exposure to ETS and family allergic history to calculate adjusted odds rations (aOR), excluding all the factors which impacted the relationship between children's health and redecorated housing environment, and expressed as aOR with 95\% confidence interval (95\% CI ). Stratified analysis was applied (stratified for gender, family allergic history and open window frequently), using the same model. Analyses were considered to be statistically significant if the p-value was less than 0.05 , and statistical significance was defined by a two-sided alpha level of $0.1 \%$, $1 \%$ and $5 \%$, and represented with $* * *, * *$ and $*$, respectively.

\section{Results and Discussion}

The survey was performed in 5,299 pre-school children in urban areas in Chongqing. the percentages of children in each age group were $0.31 \%, 2.34 \%, 20.0 \%, 32.4 \%, 29.6 \%, 14.1 \%, 1.10 \%$ and $0.08 \%$, for $1,2,3,4,5,6,7$ and 8 years old respectively. As children aged 1, 2, 7 and 8 were represented in small numbers, so they were excluded. Also questionnaires with missing information on new furniture, renovation, gender and age were excluded. Thus, 4579 children, aged $3 \sim 6$ years old were selected for further analyses, of whom 2,350(51.3\%) were boys and 2,229 (48.7\%) were girls.

Children in houses having new furniture and new decoration activities one year before pregnancy have higher prevalences of all health indicators except for eczema and related symptoms. During pregnancy and 0-1years of age of children, new furniture and new decoration are risk factors for eczema ever. Associations between asthma and allergies among children and redecorated housing environments were calculated by multivariate logistic regression models. After adjusting for the confounding factors (adjusted OR), some significantly positive associations disappeared, but still with a marginal significance. Overall, both buying new furniture and having new decoration one year before pregnancy had positive associations with children's allergies diseases (except eczema) compared to other periods. Having new furniture and new decoration during pregnancy and between 0-1 year old children were risk factors for eczema.

By stratifying for family allergic history (Yes vs. No), we investigated the associations between redecorated housing environments and asthma and allergies (Table 1-3). Whether children had family allergic history or not, exposed to redecorated housing environments or not had much higher prevalence of the studied diseases than those without redecorated housing environments. Children having no family allergic history had more wheezing and eczema (both ever and in the past year) than those had family allergic history, but for dry cough in the past year it was opposite. 
Table 1. Adjusted odds ratios between asthma and new furniture or new decoration, stratified according to family allergic history ${ }^{\text {a }}$

\begin{tabular}{|c|c|c|c|c|c|c|c|c|}
\hline & \multicolumn{2}{|c|}{ Wheezing, ever } & \multicolumn{2}{|c|}{ Wheeze, IPY ${ }^{b}$} & \multicolumn{2}{|c|}{ Dry cough, IPY b } & \multicolumn{2}{|c|}{ D-asthma } \\
\hline & $\mathrm{g}_{+}$ & $\mathrm{h}_{-}$ & $\mathrm{g}_{+}$ & $\mathrm{h}_{-}$ & $\mathrm{g}_{+}$ & $\mathrm{h}_{-}$ & $\mathrm{g}_{+}$ & $\mathrm{h}_{-}$ \\
\hline \multicolumn{9}{|c|}{ New furniture } \\
\hline \multirow{2}{*}{$\mathrm{BP}^{\mathrm{c}}$} & 1.05 & $1.50 * * *$ & 0.86 & $1.23 *$ & $1.67 *$ & 1.15 & 1.39 & 1.23 \\
\hline & $0.65 \sim 1,68$ & $1.19 \sim 1.87$ & $0.54 \sim 1.38$ & $1.00 \sim 1.53$ & $1.02 \sim 2.73$ & $0.92 \sim 1.43$ & $0.83 \sim 2.32$ & $0.88 \sim 1.70$ \\
\hline \multirow{2}{*}{$\mathrm{DP}^{\mathrm{d}}$} & 0.76 & 1.21 & 0.86 & 1.18 & 0.70 & 1.24 & 0.63 & 1.04 \\
\hline & $0.39 \sim 1.47$ & $0.89 \sim 1.63$ & $0.47 \sim 1.59$ & $0.90 \sim 1.56$ & $0.35 \sim 1.39$ & $0.93 \sim 1.64$ & $0.48 \sim 1.07$ & $0.67 \sim 1.62$ \\
\hline \multirow{2}{*}{$B Y^{e}$} & 1.04 & 1.05 & 1.12 & 1.18 & 1.14 & 1.09 & 0.78 & 1.14 \\
\hline & $0.58 \sim 1.86$ & $0.79 \sim 1.39$ & $0.64 \sim 1.96$ & $0.91 \sim 1.51$ & $0.62 \sim 2.10$ & $0.84 \sim 1.42$ & $0.40 \sim 1.52$ & $0.78 \sim 1.68$ \\
\hline \multirow{2}{*}{$A Y^{f}$} & 0.82 & 0.92 & 0.98 & 1.03 & 1.27 & 1.73 & 0.73 & 1.18 \\
\hline & $0.53 \sim 1.27$ & $0.75 \sim 1.13$ & $0.64 \sim 1.49$ & $0.85 \sim 1.23$ & $0.82 \sim 1.99$ & $0.97 \sim 1.42$ & $0.45 \sim 1.19$ & $0.89 \sim 1.56$ \\
\hline \multicolumn{9}{|c|}{ New decoration } \\
\hline \multirow{2}{*}{$\mathrm{BP}^{\mathrm{c}}$} & 0.94 & $1.52 * *$ & 0.76 & 1.14 & 1.60 & 1.00 & 1.71 & 1.30 \\
\hline & $0.52 \sim 1.69$ & $1.12 \sim 2.06$ & $0.41 \sim 1.40$ & $0.84 \sim 1.54$ & $0.89 \sim 2.86$ & $0.73 \sim 1.37$ & $0.93 \sim 3.14$ & $0.84 \sim 2.01$ \\
\hline \multirow{2}{*}{$\mathrm{DP}^{\mathrm{d}}$} & 0.70 & $1.68 *$ & 0.73 & 0.94 & 0.77 & 1.55 & 1.16 & $1.83 *$ \\
\hline & $0.26 \sim 1.88$ & $1.05 \sim 2.70$ & $0.27 \sim 1.94$ & $0.57 \sim 1.57$ & $0.27 \sim 2.19$ & $0.99 \sim 2.42$ & $0.02 \sim 1.21$ & $1.02 \sim 3.29$ \\
\hline \multirow{2}{*}{$B Y^{e}$} & 1.11 & 1.07 & 1.12 & 1.23 & $3.37 *$ & 1.43 & 1.98 & 0.74 \\
\hline & $0.39 \sim 3.12$ & $0.64 \sim 1.79$ & $0.40 \sim 3.15$ & $0.78 \sim 1.94$ & $1.24 \sim 9.16$ & $0.92 \sim 2.24$ & $0.70 \sim 5.60$ & $0.32 \sim 1.71$ \\
\hline \multirow{2}{*}{$A Y^{f}$} & 0.92 & 1.20 & 1.23 & 1.17 & 1.18 & 1.19 & 0.86 & 1.33 \\
\hline & $0.55 \sim 1.52$ & $0.93 \sim 1.53$ & $0.76 \sim 2.00$ & $0.93 \sim 1.47$ & $0.71 \sim 1.96$ & $0.94 \sim 1.50$ & $0.49 \sim 1.51$ & $0.96 \sim 1.85$ \\
\hline
\end{tabular}

Table 2. Adjusted odds ratios between rhinitis and new furniture or new decoration, stratified according to family allergic history ${ }^{\text {a }}$

\begin{tabular}{ccccccc}
\hline & \multicolumn{2}{c}{ Rhinitis, ever } & \multicolumn{2}{c}{ Rhinitis, IPY $^{\mathrm{b}}$} & \multicolumn{2}{c}{ D-rhinitis } \\
\cline { 2 - 7 } & $\mathrm{g}_{+}$ & $\mathrm{h}_{-}$ & $\mathrm{g}_{+}$ & $\mathrm{h}_{-}$ & $\mathrm{g}_{+}$ & $\mathrm{h}_{-}$ \\
\hline \multicolumn{2}{c}{ New furniture } & & & & & \\
$\mathrm{BP}^{\mathrm{c}}$ & 1.19 & 1.16 & 1.50 & 1.07 & 1.64 & 0.96 \\
& $0.76 \sim 1.86$ & $0.97 \sim 1.39$ & $0.95 \sim 2.37$ & $0.89 \sim 1.28$ & $0.92 \sim 2.91$ & $0.64 \sim 1.44$ \\
$\mathrm{DP}^{\mathrm{d}}$ & 1.18 & 1.09 & 0.78 & $1.26^{*}$ & 0.86 & 1.38 \\
& $0.67 \sim 2.09$ & $0.86 \sim 1.37$ & $0.44 \sim 1.37$ & $1.00 \sim 1.59$ & $0.39 \sim 1.89$ & $0.86 \sim 2.19$ \\
$\mathrm{BY}^{\mathrm{e}}$ & 1.67 & 1.01 & 1.53 & 1.08 & 1.28 & 1.12 \\
& $0.97 \sim 2.89$ & $0.82 \sim 1.24$ & $0.89 \sim 2.64$ & $0.88 \sim 1.33$ & $0.64 \sim 2.56$ & $0.72 \sim 1.75$ \\
$\mathrm{AY}^{\mathrm{f}}$ & 1.28 & 1.03 & 1.02 & 1.02 & 0.90 & 0.84 \\
& $0.85 \sim 1.91$ & $0.89 \sim 1.19$ & $0.68 \sim 1.53$ & $0.87 \sim 1.18$ & $0.52 \sim 1.57$ & $0.60 \sim 1.17$ \\
$\mathrm{New}$ & decoration & & & & & \\
$\mathrm{BP}^{\mathrm{c}}$ & 1.56 & 1.25 & 1.44 & 1.11 & 1.67 & 1.05 \\
& $0.88 \sim 2.76$ & $0.97 \sim 1.59$ & $0.82 \sim 2.53$ & $0.86 \sim 1.42$ & $0.86 \sim 3.22$ & $0.61 \sim 1.79$ \\
$\mathrm{DP}^{\mathrm{d}}$ & 0.94 & 1.17 & 0.53 & 0.97 & 0.88 & 1.54 \\
& $0.40 \sim 2.22$ & $0.79 \sim 1.73$ & $0.22 \sim 1.27$ & $0.65 \sim 1.45$ & $0.28 \sim 2.74$ & $0.76 \sim 3.12$ \\
$\mathrm{BY}^{\mathrm{e}}$ & 1.42 & 0.91 & 1.91 & 1.06 & 2.68 & 1.00 \\
& $0.52 \sim 3.85$ & $0.62 \sim 1.35$ & $0.68 \sim 5.35$ & $0.72 \sim 1.55$ & $0.85 \sim 8.41$ & $0.43 \sim 2.31$ \\
$\mathrm{AY}^{\mathrm{f}}$ & 0.88 & 1.15 & 1.02 & 1.12 & 0.97 & 1.16 \\
& $0.56 \sim 1.39$ & $0.96 \sim 1.39$ & $0.64 \sim 1.62$ & $0.93 \sim 1.35$ & $0.52 \sim 1.80$ & $0.79 \sim 1.71$ \\
\hline
\end{tabular}


Table3. Adjusted odds ratios between eczema and new furniture or new decoration, stratified according to family allergic history ${ }^{\mathrm{a}}$

\begin{tabular}{|c|c|c|c|c|}
\hline & \multicolumn{2}{|c|}{ Eczema, ever } & \multicolumn{2}{|c|}{ Eczema, IPY b } \\
\hline & $\mathrm{g}+$ & h- & $\mathrm{g}+$ & h- \\
\hline \multicolumn{5}{|c|}{ New furniture } \\
\hline \multirow{2}{*}{$\mathrm{BPc}$} & 1.21 & 1.11 & 1.13 & 0.89 \\
\hline & $0.75 \sim 1.96$ & $0.91 \sim 1.36$ & $0.65 \sim 1.98$ & $0.68 \sim 1.16$ \\
\hline \multirow{2}{*}{$\mathrm{DPd}$} & 1.61 & 1.14 & 1.21 & 1.03 \\
\hline & $0.89 \sim 2.92$ & $0.88 \sim 1.48$ & $0.62 \sim 2.37$ & $0.73 \sim 1.43$ \\
\hline \multirow{2}{*}{$\mathrm{BYe}$} & 1.37 & $1.43^{* *}$ & 1.19 & 1.01 \\
\hline & $0.78 \sim 2.42$ & $1.14 \sim 1.79$ & $0.62 \sim 2.28$ & $0.74 \sim 1.37$ \\
\hline \multirow{2}{*}{ AYf } & 0.97 & 1.11 & 0.98 & 1.04 \\
\hline & $0.63 \sim 1.50$ & $0.94 \sim 1.32$ & $0.60 \sim 1.62$ & $0.83 \sim 1.29$ \\
\hline \multicolumn{5}{|c|}{ New decoration } \\
\hline \multirow{2}{*}{$\mathrm{BPc}$} & 1.21 & 1.19 & 0.54 & 1.17 \\
\hline & $0.68 \sim 2.18$ & $0.90 \sim 1.58$ & $0.24 \sim 1.22$ & $0.83 \sim 1.65$ \\
\hline \multirow{2}{*}{ DPd } & 1.44 & $1.76^{* *}$ & 1.06 & $1.91 * *$ \\
\hline & $0.58 \sim 3.60$ & $1.17 \sim 2.66$ & $0.37 \sim 3.01$ & $1.19 \sim 3.06$ \\
\hline \multirow{2}{*}{ BYe } & 1.31 & $1.61^{*}$ & 0.82 & 1.46 \\
\hline & $0.47 \sim 3.68$ & $1.07 \sim 2.41$ & $0.23 \sim 2.96$ & $0.89 \sim 2.40$ \\
\hline \multirow{2}{*}{ AYf } & 0.94 & 1.18 & 0.94 & $1.47^{* *}$ \\
\hline & $0.57 \sim 1.55$ & $0.96 \sim 1.46$ & $0.53 \sim 1.68$ & $1.13 \sim 1.90$ \\
\hline
\end{tabular}

a Odds ratios were adjusted for gender, age, house site, living near a main road or highway, exposure to ETS and family allergic history, ${ }^{* *} \mathrm{P}<0.001,{ }^{*} \mathrm{P}<0.01,{ }^{*} \mathrm{P}<0.05$; b IPY: in the past year; c BP: one year before pregnancy; d DP: during pregnancy; e BY: between $0-1$ year old; f AY: after one year old; $\mathrm{g}+$ : family allergic history; $\mathrm{h}$-: no family allergic history

Asthma is becoming a common disease affecting about 18.9 million adults and 7.1 million children in the United States, more than 20 million people in China, and 300 million people worldwide. In 2010, the prevalences of asthma among children were $3.15 \%, 7.45 \%$ and $2.09 \%$ in Beijing, Chongqing and Guangzhou respectively, showing a sharp upward trend compared to the data ten years ago, which were $2.69 \%, 4.63 \%$ and $1.33 \%$, Chongqing having a high prevalence [16]. Chongqing had the highest percentage and fastest growth rate of asthma in children.

In epidemiological studies, selection bias may affect the results. 55 kindergartens in three districts in Chongqing were randomly selected, and include all children aged 3-6 from the cross-sectional study. Moreover children's health status wasn't known, the sample size is reasonably large $(5,299 / 7,117)$, and the response rate $(74.5 \%)$ is high. So, in this study, selection bias influence is excluded.

The study suggests an influence of redecorated housing environments on asthma and allergies. It could be concluded that one year before pregnancy is more of a risk factor than others, it leads to a higher risk in terms of the increased prevalence of asthma and rhinitis compared to other periods, although few people have had this activity in early childhood. Almost $18.8 \%$ and $5.2 \%$ of all houses with 3-6 year-old children had new furniture and new decoration one year before pregnancy respectively. Franck's study reported that redecoration during pregnancy could increases the risk for respiratory diseases in early childhood [17]. Its conclusion is a little different from this study, because Franck's study only had two timepoints during pregnancy and at children's age of one, while this study had four timepoints one year before pregnancy, during pregnancy, between $0-1$ year old and after one year old. Risks during pregnancy and between $0-1$ years old related to eczema are consistent with Olf Herbarth et al.'s study indicating that the strongest effect on children's eczema and allergies was renovation which took place just around birth [18].

Modern home furniture is most made of artificial board and synthesized resin, which may strongly emit formaldehyde, benzene, other VOCs [19]. Paints and lacquers, glues, and adhesives would also emit a large number of VOCs and formaldehyde [20]. Exposed to formaldehyde had an increased risk for childhood wheeze, asthma and bronchitis [14]. Indoor concentrations of VOCs and benzene would strongly increase the prevalence of asthma in children [21]. 
Despite the fact that the concentration of indoor formaldehyde would decrease after decoration, it needs more than one year to reach the national standard [22]. A Zhaoqing's study determined the concentration of indoor formaldehyde in 100 recent decorated residential apartments [54]. Results showed the rations of those exceeding the standard formaldehyde concentration were $90.13 \%$, $11.79 \%$ and $9.27 \%$ one month after decoration, one year later and two year later. A study in Hangzhou conducted in 2,324 rooms decorated within one year in 2007-2009, reported that 38.9\% of samples exceeded the Chinese National Standard [23].

VOC emissions from the sheet products decreased more quickly than formaldehyde, reaching low levels within two weeks, except for MDF which was found to become a low-level source of hexanal after several months [24]. A survey by Wang et al. indicated that in decorated houses using natural ventilation, the concentrations of TVOC would be reduced to the national standards after five months [25]. In this study, very few people had new furniture and new decoration during pregnancy and between $0-1$ years of age of children from Table 3 . It could be inferred that most parents avoid having new furniture or new decoration when they were pregnant or in early childhood, which are sensitive periods for their children's health, and many parents are aware that high levels of chemicals would emit from new furniture and new decoration, which are risk factors for their children's health.

A LARST study showed VOCs released during redecoration work have a long-term effect on the development of obstructive airway illnesses via another pathophysiological mechanism [26]. VOCs enter the body through the lungs and are absorbed by the blood [27]. They may influence the immune regulation of TH-cells. TH1-cells producing INF- $\gamma$ and TH2-cells producing IL4 were reduced with raised VOC concentrations in indoor air [28]. Moreover TH2-cell mediated adaptive immune responses have been widely recognized as a crucial component of allergic disease. Genes important for TH1 versus TH2 T cell polarization have been implicated in asthma and allergy [29].

Ventilation is a good way to reduce human exposure to indoor pollutants [30]. High outdoor air flow rate had been shown to be association with an decrease of VOCs and poor indoor air quality. Thus a low ventilation rate may a risk factor for children's asthma and allergies [31]. In this study, opening windows in children's room more frequently had negative relation with asthma and allergies. But the boundary ventilation rate can't be calculated from the questionnaire, it needs further analysis.

Our findings show that children may have increased asthma and allergies under redecorated housing environments because new furniture and new decoration release VOCs, which could affect children's health.

\section{Conclusion}

Redecorated housing environments were positively associated with children's asthma and allergies in Chongqing, especially one year before pregnancy. Improving home ventilation probably can reduce related diseases among children. The results of this study suggest that to protect children from asthma and allergies, exposure to new furniture and new decoration should be minimised in children's early life.

\section{References}

[1]. Blondel A., Plaisance H. Screening of formaldehyde indoor sources and quantification of their emission using a passive sampler. Build Environ, 2011, 46: 1284-1291.

[2]. Wang Y., Shen J., Zhu H., et al. Determination of volatile organic compound emission from wood-based panels. Proceedings of the 55th International Convention of Society of Wood Science and Technology August, 2012, AP1-4.

[3]. He Z. K., Zhang Y. P., Wei W. J. Formaldehyde and VOC emissions at different manufacturing stages of wood-based panels. Building and Environment, 2012, 47: 197-204.

[4]. Zhao L. F., Cui M. Investigation on indoor air pollution in newly decorated houses in Jiaozuo city. J Environ Health, 2007, 24: 712-714. 
[5]. Li S. G. Investigation on indoor air pollution to health in decorated houses. Master Dissertation. Lilin: Lilin University, 2004.

[6]. Yue W., Jin X. B., Pan X. C., et al. Relationship between indoor air formaldehyde exposure and allergic asthma in adults. Chin J Public Health, 2004, 20: 904-906.

[7]. Garrett M.H., Hooper M.A., Hooper B.M., et al. Increased risk of allergy in children due to formaldehyde exposure. Allergy, 1999, 54: 330-337.

[8]. Koren H., Graham D., Devlin R. Exposure of humans to volatile organic mixture. III. Inflammatory response. Arch Environ Health, 1992, 47:39-44.

[9]. Liu K., Cheng X. D., Lin P. Study on the situation of formaldehyde \& TVOC's pollution to the air of decorated indoors and its effect to adult on health. Jiangsu Prev Med, 2005, 16: 12-14.

[10]. Smedje G., Norback D., Edling C. Asthma among secondary schoolchildren in relation to the school environment. Clin. Exp. Allergy, 1997, 27: 1270-1278.

[11]. Dales R., Raizenne M. Residential exposure to volatile organic compounds and asthma. J. Asthma, 2004, 41: 259-270.

[12]. Baker-Laporte P., Banta J. C., Elliott E. Prescriptions for a healthy house. New Society Publishers, 2005.

[13]. Wu F., Jacobs D., Mitchell C. et al. Improving indoor environmental quality for public health: impediments and policy recommendations. Environ Health Perspect, 2007, 115: 953-95.

[14]. Wieslander G., Norback D., Bjornsson E., Janson C., Boman G. Asthma and the indoor environment: the significance of emission of formaldehyde and volatile organic compounds from newly painted indoor surfaces. Int Arch Occup Environ Health, 1997,69: 115-124.

[15]. Yrieix C., Dulaurent A., Laffargue C., et al. Characterization of VOC and formaldehyde emissions from a wood based panel: Results from an inter-laboratory comparison. Chemosphere, 2010, 79:414-419.

[16]. Franck U., Weller A., Röder S. W., et al. Prenatal VOC exposure and redecoration are related to wheezing in early infancy. Environ Int. 2014, 73:393-401.

[17]. Herbarth O., Fritz G. J., Rehwagen M., et al. Association between indoor renovation activities and eczema in early childhood. Int. J. Hyg. Environ.-Health, 2006, 209: 241-247.

[18]. Wen H. J., Chen P. C., Chiang T. L., et al. Predicting risk for early infantile atopic dermatitis by hereditary and environmental factors. Br J Dermatol, 2009, 161:1166-1172.

[19]. Yu C. W. F., Crump D. R. Small chamber tests for measurement of VOC emissions from flooring adhesives. Indoor Built. Environ., 2003, 12: 299-310.

[20]. Kim S., Kim H. J., Moon S.J. Evaluation of VOC emissions from building finishing materials using a small chamber and VOC analyzer. Indoor Built. Environ., 2006, 15: 511-523.

[21]. Ware J. Respiratory and irritant health effects of ambient volatile organic compounds. The Kanawha County Health Study. Am J Epidemiol, 1993, 137:1287-1301.

[22]. Huang J. L., Liu Z. Y., Zhu C. M., et al. An investigation of indoor decoration and air pollution in Changsha city. Practical Preventive Medicine, 2003,10: 907-908.

[23]. Jiang S. F., Yu L. Q., Li J., et al. Health effect caused by indoor formaldehyde on decorated apartments. Chinese Journal of Coal Industry Medicine, 2006, 9: 879-881.

[24]. Wang L. Investigation of TVOC concentration in indoor air. North Environment, 2004, 29: 34-35. 
[25]. Diez U., Rehwagen M., Rolle-Kampczyk U., et al. Redecoration of apartments promotes obstructive bronchitis in atopy risk infants-results of the LARS Study. Int. J. Hyg. Environ. Health, 2003, 206: 173-179.

[26]. Ashley D. L., Bonin M. A., Cardinali F. L., et al. Measurement of volatile organic compounds in human blood. Environ. Health Perspect, 1996, 104: 871-877.

[27]. Lehmann I., Rehwagen M., Diez U., Seiffarth A., et al. Enhanced in vivo IgE production and T cell polarization to the type 2 phenotype in association with indoor exposure to VOC: results of the LARS study. Int. J. Hyg. Environ. Health, 2001, 204: 211- 221.

[28]. Genuneit J., Cantelmo J. L., Weinmayr G., et al. A multi-centre study of candidate genes for wheeze and allergy: the International Study of Asthma and Allergies in Childhood Phase 2. Clin Exp Allergy, 2009, 39:1875-1888.

[29]. Zhou H., Hong X., Jiang S., Dong H., et al. Analyses of associations between three positionally cloned asthma candidate genes and asthma or asthma-related phenotypes in a Chinese population. BMC Med Genet, 2009, 10:123.

[30]. Bornehag C. G., Sundell J., Hagerhed-Engman L., Sigsgaard T. Association between ventilation rates in 390 Swedish homes and allergic symptoms in children[J]. Indoor Air 2005, 15:275-280.

[31]. Smedje G., Norback D. New ventilation systems at select schools in Sweden effects on asthma and exposure[J], Arch. Environ. Health, 2000, 55:18-25. 